\title{
社会神経科学は社会的認知研究に何をもたらすか
}

\author{
東海大学 \\ 尾崎 由佳
}

\section{The benefits from social neuroscience to social cognition research}

\author{
Yuka OzaKI \\ Student Project Center, Tokai University \\ 4-1-1 Kitakaname, Hiratsuka, Kanagawa 259-1292
}

Social cognition research has been developed mainly with methodologies in social psychology since its early years. Social neuroscience, originated in 1990s, has promoted a great expansion of social cognition research by bringing in a new perspective and methodologies, and there is a growing expectation for future research. The purpose of this paper is to discuss how social cognition research has benefitted from the emergence of social neuroscience. The benefits are discussed from the following perspectives; (a) examination of hypothetical concepts, (b) examination of psychological processes, and (c) examination of unconscious processes. (Japanese Journal of Physiological Psychology and Psychophysiology, 28(1) : 6774, 2010.)

Key words : social cognition, social neuroscience, cognitive neuroscience, social psychology

【要 約】社会的認知研究は，その創始当初から主に社会心理学の手法を主に研究が進められてきた。1990 年代 に社会神経科学が興隆して新たな視点と手法が持ち込まれたことにより, 社会的認知研究は大きな進展を遂げつ つあり, 今後の展開にも期待が集まっている。本論文の目的は, 社会神経科学が社会的認知研究にもたらす恩恵 と今後の可能性について, (a) 仮説的構成概念の検証, (b) プロセスモデルの検証, (c) 非意識的プロセスの検証と いう3 点から論じることである。 
元来, 社会的文脈における認知は社会的認知 (social cognition) と呼ばれ，主に社会心理学者によって精力 的に研究が進められてきた。社会的認知の研究が隆盛 を極めるようになったのは 1960 年代から 1970 年代ご ろであり, 当時から現在にいたるまで社会心理学の主 流なテーマのひとつを占めている。一方, 従来の認知 神経科学は, 社会的文脈から切り離された “純粋な認 知”に焦点をあてて人間の認知システムを解明してき た。しかし，人間の認知システムは社会の中で機能す るために進化したものであり，社会的文脈においてこ そ，その真価を発揮する。その点に着目し，認知神経 科学者が社会的文脈における認知をテーマとして取り 上げるようになったのは，比較的近年のことである。 この流れを受けて社会神経科学 (social neuroscience) と いう言葉が創出された (Cacioppo \& Berntson, 1992)。 以来ほぼ 20 年が過ぎた。現在では, この領域におい て感情・態度・推論・意思決定など幅広い心理現象が あつかわれるようになり，研究蓄積が進みつつある。 近年, Social Neuroscience (2006 年 3 月創刊) やSocial Cognitive and Affective Neuroscience (2006 年6月創刊) などと名付けられた学術誌が刊行されるようになった ことも，この領域の急速な発展度合いを表していると 言えよう。

約 20 年前に認知神経科学者が社会的認知に興味を 持ち始めたのと同様, 社会心理学者も社会神経科学的 な視点および技法に強い関心を示すようになった。そ の関心度の高さは, 社会心理学領域において最も権威 ある学術誌のひとつである Journal of Personality and Social Psychologyの 2003 年 10 月号が社会神経科学の 特集にあてられたことにも，その一端が表れていると 言えよう。また, Handbook of Social Psychology という 伝統ある書物の章構成にも, 近年, 特筆すべき変化が 見られた。この本は 1935 年に初版が発行されて以来, すでに第 5 版を重ねている。その第 4 版 (Gilbert, Fiske, \& Lindzey, 1998) では社会神経科学をメインに取 り上げた章は見当たらないが，最近発刊された第 5 版 (Fiske, Gilbert, \& Lindzey, 2010)では “Social Cognitive Neuroscience” と "Social Psychophysiology and Embodiment" という2 章が設けられ，多くの紙面をあてて紹介され るようになつた。社会心理学者にとつて, 社会神経科 学のプレゼンスが近年急速に大きくなつた様子が伺わ れる。つまり，以前は社会心理学分野において専ら扱
われてきた社会的認知というテーマに，1990 年代よ り社会神経科学という新たな視点と技法が導入され, 大きな注目を集めるようになった。

このような新展開により, 社会的認知研究にどのよ うな恩恵と発展がもたらされたのであろうか。従来の 社会心理学の技法だけでは検証不能あるいは困難であ つたことを, 社会神経科学はどのようにして解き明か すことができるのだろうか。これらの問いに対してど のような答えを導き出すかは, 社会神経科学という比 較的新しい分野をこれまでの人間科学研究の流れの中 に位置づけるために, そして今後の方向性や可能性を 見極めるためにも，重要なポイントとなるだろう。

そこで本稿は「社会神経科学は社会的認知研究に何 をもたらすか」という論題を設定した。本稿の筆者で ある尾崎は, 社会心理学分野の専門教育を受けて社会 的認知研究を進めてきたが, 近年になって社会神経科 学に興味を持ち始めたという経緯がある。このような 経験に基づき, 社会心理学者の視点から, 社会神経科 学の持つ魅力と可能性について述べていきたいと思う。

次章以降では, 社会神経科学が社会的認知研究にも たらす恩恵と今後の可能性を, (a) 仮説的構成概念に ついて, (b) プロセスモデルについて, (c) 非意識的プ ロセスについてという3つのサブセクションを設けて 順に論じる。

\section{仮説的構成概念について}

社会的認知研究では，モデルを構築する際にしばし ば仮説的構成概念が用いられる。たとえば, 認知的不 協和 (cognitive dissonance) や生理的覚醒 (physiological arousal), 認知資源 (cognitive resource), 制御資源 (regulatory resource), そして各種の動機づけ (motivation)などは，古典的時代から現在にいたるま で社会心理学者が頻繁に用いてきた仮説的構成概念で あると言えよう。これらは，その存在を仮定すること によって様々な心理現象が説明可能になるのだが, 直 接的にその存在を示すことが困難あるいは不可能な心 理的概念である。この仮説的構成概念の存在を証明し ようとすると, トートロジーに陥りやすいという難点 がある。なぜならば,「仮説的構成概念 Xが存在する から現象 Yが生じる」とモデルにおいて仮定してい るにもかかわらず,「現象 Y が生じるか否かにによっ て構成概念 Xの存在の有無が推測される」といった 
形でしかその存在を証する術がないのである。たとえ ば認知的不協和理論では「ふたつの認知的要素の間に 矛盾があったときに認知的不協和（仮説的構成概念 X) が発生するため, その不協和を低減しようとして態度 変化が起きる（現象 Y)」と想定されている。にもか かわらず, 実証研究においては, 実験操作によって想 定どおりに認知的不協和が発生したのか否かを議論す るときに「態度変化が見られたため（現象 Y), 参加 者は認知的不協和を感じていたと推測される（仮説的 構成概念 X)」という論じ方を目にすることがある。 これではトートロジーであるという批判を免れない。

このようなトートロジーに陥らず，より妥当な方法 を用いて構成概念 $\mathrm{X}$ の存在を証明したいのであれば, 現象 Y 以外の何らかの客観的指標を用いて検証する 必要がある。しかし, 従来の社会心理学においては外 顕的に表出される言語的／非言語的反応を指標として 用いることがほとんどであったため, 心理プロセスに 内在しており外顕的に表出されない仮説的構成概念の 存在を検証することは困難であった。

このような苦境に光明を投げかけることになったの が, 社会神経科学的手法である。脳機能画像や生理的 指標を用いれば, 外顕的な言語報告や行動に表出され ない内的心理活動の様子をオンラインで測定すること が可能になる。たとえば, 前述の認知的不協和に関し て fMRI を用いて検討した例として Van Veen，Krug， Schooler, \& Carter (2009) の研究が挙げられる。この研 究では，狭苦しいfMRI スキャナ内に閉じ込められた 参加者に「スキャナの中は快適だ」と発言させること によって, 自らの主観的体験と発言内容の間に認知的 不協和を生じさせることが試みられた。その結果, 背 側前帯状皮質 (dorsal anterior cingulate cortex) の活性化 が見られた。前帯状回皮質は認知的暮藤と態度変容に 関連する部位であることから, 参加者は認知的不協和 を経験していたと考えられる。勿論, 脳部位の活性化 は間接的な指標であり, 実際にどのような心理的処理 が行われていたかについては推測の域を出ない。しか し, 態度測定以外の客観的指標によって認知的不協和 の経験を示唆する結果が得られたことは，この仮説的 構成概念が態度変容のプロセスに介在していることを 支持するものであり, 認知的不協和理論の妥当性を示 す重要な証拠であると言えよう。

一方, 社会神経科学的手法によって検証されたこと
により，モデルを構成する要因としての妥当性が疑問 視されるようになった仮説的構成概念もある。たとえ ば, 生理的覚醒という概念は, 社会的促進 (social facilitation)や社会的抑制 (social inhibition) といつた現 象を説明するために考案された仮説的構成概念である (Thibaut \& Kelley, 1959; Zajonc, 1965)。行為者がある課 題に取り組むとき，その場に他者が居合わせることに よってパフォーマンスが向上することを社会的促進, 逆に低下することを社会的抑制と呼んでいる。このよ うな現象が生じる理由として, Zajonc (1965) は行為者 が他者の存在を認識することによって生理的覚醒が高 まり，その結果として優勢な反応 (dominant responses) が促進されると考えた。したがつて, 簡単な課題や繰 り返し練習した課題であれば生理的覚醒が高まると優 勢な反応として優れたパフォーマンスを示すことがで きるだろうが，困難な課題や初めて取り組む課題の場 合は生理的覚醒が高まると優勢な反応として劣ったパ フォーマンスが示されるだろうというのがZajonc の モデルである。しかし, 後年になって数多くの研究者 が生理的指標を用いてこのモデルを検証しょうとした が，それらの結果報告をメ夕分析したところ生理的覚 醒とパフォーマンスの間に明確な関係性はほとんど示 されなかったという(Bond \& Titus, 1983)。ところが, 挑戦 ・劦威動機に関する生理心理学的モデル (Blascovich, 2008; Blascovich \& Tomaka, 1996)にもとづ いて Blascovich, Mendes, Hunter, \& Salomon (1999)が行 つた実験では, よく練習した課題においては他者の存 在によって心拍出量が増加し末梢血管抵抗が減少する という挑戦反応 (challenge responses) が生じてパフォ ーマンスを向上させ, 逆に初めて取り組む課題におい ては心拍出量が減少し末梢血管抵抗が増加するという 劦威反応 (threat responses) が生じてパフォーマンスを 減退させることが明らかになった。つまり, 社会的促 進と社会的抑制という 2 種類の現象はそれぞれが挑戦 反応と劦威反応という異なる要因によって影響を受け ていることが示唆され, 両現象とも生理的覚醒という 単一の要因によって媒介されるというZZajonc のモデ ルは反駁されたことになる。

このように，モデルに含まれる仮説的構成概念を検 証するという点について, 従来の社会心理学において はトートロジーに陥りがちであり多くの場合は不問に 付されてきたが, 社会神経科学の発展によって科学的 
に適切な手法をもつて詳細に検証することが可能にな つた。このような社会神経科学的な手法を用いた研究 を今後も進めていくことにより, 社会的認知研究にお いてこれまで想定されてきた仮説的構成概念がどのく らい妥当性の高いものであるかを改めて検証しなおす ことができるだろう。

\section{プロセスモデルについて}

社会的認知研究の歴史を紐解いてみると, 同一の心 理現象を説明するために複数の研究者が異なるプロセ スモデルが提唱し，いずれが妥当であるかについて議 論が交わされてきたという事例がいくつも存在する。 たとえば，ステレオタイプの適用に関する二重処理モ デル (Brewer, 1988) と連続体モデル (Fiske \& Neuberg, 1990)，属性帰属に関する三段階モデル (Gilbert, 1989) と二段階モデル (Trope, 1986), 平均以上効果に関する 熱い認知 (Dunning, 1993) と冷たい認知 (Kruger, 1999) などが著名な論争として挙げられる。

従来の社会心理学においては, これらの議論におい てモデルの妥当性を比較検証する際, 各モデルから異 なる予測が導かれるような実験条件を設け，観測され た外的表出（判断結果や行動傾向）がいずれのモデル の予測を支持するかを確かめるという方法が取られて きた。しかし，この検証法にはいくつかの難点がある。 まず，実験条件の設定が難しい。同じ現象を扱ってい るモデルから異なる予測が導かれるような特殊な実験 操作や状況を用意することが必要となるため，その実 験アイディアの考案時には相当の創意工夫を要すると ともに, 実験実施時には細心の注意が求められる。こ のような苦心の結果, 非日常的で特殊な実験状況がで きあがってしまい,このような実験で得られた結果を どこまで一般化できるかが疑問視されるような場合も ある。また，もし実験が成功し，いずれかのモデルを 支持するような結果が得られたとしても, 同じ実験結 果を説明できる他のモデルが表れる可能性を否定でき ず，次々と新しいモデルがあらわれて切りがなくなつ てしまう恐れもある。こういつた様々な問題があるた め, モデル間の妥当性比較には困難が伴うことが多か つた。そのため, 前段落で紹介したモデル間の論争の 数々も, ぞちらのモデルの方が正しいのか, 未だに明 確な結論は出ていないのである。

なぜ従来の社会心理学的手法によってモデル間の妥
当性比較を試みようとすると, これほどに困難をとも なうのであろうか。その原因として挙げられるのは, プロセスモデルを検証する方法として, 最終的なアウ トプット（判断結果や行動傾向）のみを主な従属変数 として用いていることが挙げられる。つまり, プロセ スの途中でどのような処理が行われているかについて はアウトプットから推測せざるをえないのである。た とえば，ステレオタイプの適用に関する二重処理モデ ル (Brewer, 1988) と連続体モデル (Fiske \& Neuberg, 1990)の論争をとりあげて説明しょう。印象形成モデ ルは, カテゴリーにもとづいた処理のほうが特性にも とづく処理に先行すると主張した点が特徵的である。 一方, 連続体モデルは, 各処理段階においてカテゴリ 一表象が用いられるか特性表象が用いられるかという 表象の質的差異を想定していない。従来の社会心理学 において, これらのモデルの妥当性を検討するために 主に用いられてきたのは, 参加者に帰属課題を行わせ ているときに認知的負荷をかけたり, 処理に対する動 機づけを操作したりして, 判断結果がどのように異な ってくるかを調べるという方法であった (e.g., Fiske, 1988)。 しかし，これらの実験には，認知的負荷をかけること によって不自然な実験状況になることや，特殊な動機 づけの関わる事例を取り上げたために結果を一般化し づらくなってしまうことなど, 様々な問題が伴った。 結局, 従来の社会心理学的手法を用いた検証法では, カテゴリーにもとづく処理の方が特性にもとづく処理 よりもつねに先行するのか否かについて明確な結論は 出ていない (e.g., Brewer \& Harasty Feinstein, 1999)。

これに対して社会神経科学的手法を用いることの利 点は, オンライン測定による処理プロセスの検証が可 能なことである。つまり, 参加者が判断課題に取り組 んでいる際に, 同時並行して神経学的・生理学的指標 を測定すれば, どのように情報処理が進行したのかを ある程度推測できる。たとえば，前述のステレオタイ プの適用に際してカテゴリーにもとづく処理が必ず先 行するのかどうかという議論に対して, 脳機能画像等 を用いて処理プロセスのありかたを推定できる可能性 がある。たとえば, fMRI を用いた研究では, 呈示さ れた顔写真が黒人の場合の方が白人の場合よりも扁桃 体の強い活性化が観察された (Lieberman, Hariri, Jarcho, Eisenberger, \& Bookheimer, 2005)。すなわち, 参加者は黒人というカテゴリーに対して強い感情的反 
応を示したと推察される。ただし, 顔写真に対して人 種以外の判断課題を行わせるなど(Wheeler \& Fiske, 2005), 特定の実証状況下では扁桃体の活性化が弱くなる場合 もあることも明らかにされている (Krendl, Macrae, Kelley, Fugelsang, \& Heatherton, 2006; Lieberman, et al., 2005)。つまり，カテゴリーにもとづく処理とそれに 伴う感情反応が必然的に生じるとは限らないことが示 唆されたと言えよう。これらの結果は, カテゴリーに 基づく処理が先行すると主張する二重処理モデル (Brewer, 1988) よりも, 処理に際してカテゴリー表象 が用いられるか特性表象が用いられるかは状況に応じ て変化するという連続体モデル (Fiske \& Neuberg, 1990)の主張の方を支持しているのではないかと解釈 できる。この問題に関して結論を出すまでにはさらな る研究蓄積が必要であろうが, 今後の展開が注目され る。また,これらの研究において参加者が取り組んだ 課題は, 単純に顔写真を呈示するなどシンプルな課題 構成であったことも特筆すべきことである。つまり， 認知的負荷をかけるなどの不自然で複雑な実験操作を 加えなくてもプロセスの検証が充分に可能であること も, 社会神経科学的手法のもうひとつの利点だと言え る。このように, 社会神経学的手法を用いて神経学的・ 生理学的指標をオンライン測定できるようになったこ とにより, 社会的認知研究はプロセスモデルの検証方 法の幅を大きく広げることとなった。

\section{非意識的プロセスについて}

1980 年代以降, 社会心理学では非意識的プロセス への注目が急速に高まった。その結果, 社会的認知に 関する様々な現象に関して意識的プロセスと非意識的 プロセスという2つの過程が関与していることを想定 したモデルが数多く提唱された (Chaiken\& Trope, 1999)。 しかし, このような関心の高まりとともに, いくつか の疑問も生じた。

1つ目の疑問は, 意識的／非意識的プロセスは領域 固有的なものか否かという点である。当初, 各領域の 研究者がそれぞれ独自のモデルを提案したため, 各領 域の現象を説明するのに特化したモデルが乱立するこ とになった。たとえば，たとえば推論に関する直感的 /理性的システム (intuitive/rational systems; Kahneman, 2003)や，属性帰属に関する熟慮的／反射的システム (reflection/reflexion systems; Lieberman, Gaunt, Gilbert, \&
Trope, 2002)などが挙げられる。これらのモデルには 類似点もあるものの, 少しずつ異なつた主張が組み込 まれている。では, これらのモデルで想定されている 意識的／非意識的プロセスは, 領域を超えて共通する ものなのであろうか, それとも個々の領域に固有のも のなのだろうか。

$2 つ$ 目の疑問は, 意識的プロセスと非意識的プロセ スは，それぞれ独立したシステムに司られるのか，そ れとも単一のシステムによって司られるのかという点 である。先に挙げた直感的／理性的システム (Kahneman, 2003) や熟慮的／反射的システム (Lieberman, et al., 2002)などはそれぞれ独立したシス テムの存在を主張している。その一方で, 単一のシス テムによって意識的/非意識的プロセスの両方が司ら れていると主張するユニモデル (unimodel; Kruglanski \& Thompson, 1999)のような例もある。

上に挙げた $2 つ の$ 疑問に対し，これまでの社会心理 学的手法を用いた検証法では充分に納得のいく結論を 導くことができず，議論は平行線をたどるばかりであ つた。しかし, 社会神経科学的手法が導入されたこと により,これらの疑問に対して新たな切り口から検証 できる可能性が開けた。たとえば，推論・記憶・自己 制御など様々な領域に関して，それぞれ意識的プロセ スを用いる課題や非意識的プロセスを用いる課題を実 施したときに, 各課題でどのような脳部位の活性化が 見られるかを測定したとしよう。第1の可能性として, 異なる領域の課題であっても, 意識的プロセスが関与 している場合には必ず共通する特定の部位が活性化し, また非意識的プロセスが関与している場合には別の部 位が各課題に共通して活性化することが考えられる。 もしこのようなパターンが見られたとすれば，2 種類 のプロセスが独立したシステムによって司られており, さらに領域を超えてこれらのシステムが関与している 可能性が示唆されたと言える。第2の可能性としては, 意識的プロセスの関与する課題でも, 非意識的プロセ スの関与する課題でも, ほぼ同じ脳部位の活性化が見 られるかもしれない。この場合は, 単一のシステムに よって $2 つ の$ 処理が執り行われていることが推察され る。第 3 の可能性として, 各課題によって全く異なる 脳部位の活性化が観察されるかもしれない。もしそう だったとすれば，領域固有のシステムがそれぞれ働い ていたと考えるのが妥当であろう。これらの可能性に 
ついて検証するために，実際にLiberman (2007)が文 献のレビューを行ったところ, 幅広い領域の課題を通 じて，意識的プロセスには外側前頭前皮質 (lateral PFC), 外側頭頂皮質 (lateral parietal cortex), 内側前頭前 皮質 (medial PFC), 背内側前頭前皮質 (dorsomedial PFC), 楔前部 (precuneus), 内側側頭葉 (medial temporal lobe) の活性化が伴い，非意識的プロセスには扁桃体 (amygdala), 腹内側前頭前皮質 (ventromedial PFC), 外側 側頭皮質 (lateral temporal cortex), 腹側線条体 (ventral striatum) の活性化が伴うという共通のパターンが明ら かになったという。すなわち，上に挙げた第 1 の可能 性が支持されたことになる。このようなレビュー成果 に基づき, Liberman は意識的プロセスと非意識的プ ロセスは独立したシステムに司られていると結論づけ た。この主張に関しては反論もあるものの (Kruglanski \& Orehek, 2007), このような手法によって意識／非意 識の問題に取り組むことができるという可能性が示さ れたことは興味深いことであり, 今後の研究発展に期 待できる展開になってきていると言えよう。

また，非意識的プロセスに関して社会神経科学的手 法を用いることの利点としてもうひとつ挙げられるの が，言語的指標や行動的指標に表れない非意識的処理 も検出できることであろう。特に, 皮膚電位や脳波な ぞ時系列的な解析に優れた手法を使えば，時間軸上の ぞの時点で処理が生じているかをオンラインで測定可 能である。たとえば Libet, Wright, \& Gleason (1982)の 研究では，人が意図を持って行動をおこすとき，実際 の行為開始の $500 \mathrm{~ms}$ 前, そして本人が自らの意思決 定を意識するよりも $350 \mathrm{~ms}$ も早く，すでに脸内では 淮備電位が発生していることが明らかにされた。

このような社会神経学的な測定手法は, 非意識的な 心理活動がいつ, どのように生じているのかを知るた めの強力なツールである。今後, 技術的な発展ととも に検証可能な範囲もますます広がり, 社会的認知研究 によって報告されてきた様々な非意識的処理を伴う現 象も解明が進むにちがいない。たとえば，非意識的思 考 (unconscious thought)という興味深い現象が Dijksterhuisn \& Nordgren (2006)によって報告されてい る。彼らによると, 複雑な判断課題においては意識的 処理よりも非意識的処理の方が優れたパフォーマンス を示すという。たとえば，まず参加者に膨大な量の情 報を与えておき, 続いてしばらくのあいだディストラ
クター課題などに取り組ませてその情報について意識 的に考えさせないようにさせる。その後, 先程与えた 膨大な情報に関する判断課題を呈示し, 直感的に解答 させる。すると, 意識的によく熟考して解答した場合 よりも，合理的な解答を導きだすことができるという のが彼らの発見である。彼らはこの結果から, ディス トラクター課題に取り組んでいる間に “非意識的思考” が㗢くために優れたパフォーマンスが示されるのだと 論じている。しかし, 彼らが検討しているのは参加者 の解答の合理性の比較のみであり, この非意識的思考 というプロセスが実際どのように行われたのかについ ては推測に基づく議論だけにとどまっている。この非 意識的思考のプロセスに関してより直接的に検証する ためには, 脳機能画像などの手法が役立つのではない かと思われる。たとえば，上述の実験手続きにおいて ディストラクター課題中に神経的・生理的反応の測定 を行えば，課題遂行と並行して “非意識的思考” と思 われる何らかの処理が行われているかどうかを示唆す る情報が得られるかもしれない。このような検証を通 じて, この非意識的思考という現象に関する学術的理 解がさらに深められるであろう。この非意識的思考は 一例に過ぎないが, この他にも社会的認知研究におい て報告されてきた様々な現象に関わる心理プロセスを 新たな視点から解明していくために, 社会神経科学は 大いに貢献することだろう。

\section{結語}

どんな学問にも，その強みと弱みというものがある。 では，社会神経科学という分野が生まれる以前の社会 心理学と認知神経科学は, それぞれどのような強みと 弱みを持っていただろうか。社会心理学の強みは, 社 会的文脈において，どのような外的表出（言語／非言 語的行動）が生じるかを予測できることであった。た だし，その外的表出が生み出されるまでの過程でどの ような内的プロセスが関与しているかについては限定 された検証手段しかもたず，推測の域を出なかったの が弱点であった。一方, 認知神経科学は, 内的プロセ スを推察するために神経的・生理的反応を観測すると いうツールを持っていることが大きな強みであった。 ただし，まだ社会的文脈に注目を向けていなかった時 代の認知神経科学は, 人間の社会生活における外的表 出の予測において，ごく限られた予測力しかもたなか 
つた。このような社会心理学と認知神経科学の長所と 欠点がそれぞれ補い合うかたちとなって生まれたのが, 社会神経科学という新たな分野だと言えるだろう。

ただし, 社会的認知研究を推し進めていくにあたり, 現段階での社会神経科学には制約も存在する。ここで 論じたいのは，心的表象に関する問題である。心的表 象は, 社会的認知研究において最も重要視されてきた 概念のひとつである。たとえば，黒人の顔写真を呈示 された参加者は, 暴力的である・知的能力が低い・運 動能力が高い・音楽的センスがある等, 黒人カテゴリ 一に関連のある様々な心的表象を活性化させるだろう と考えられる。ただし, 関連する全ての心的表象が活 性化するわけではなく, 社会的文脈などに応じて質的 に異なったものが活性化され，その後の反応に影響を 及ぼす。つまり，社会的刺激に対してどのような表象 が活性化されるかを明らかにすることが重要な検討課 題となる。この課題に対して社会神経科学の手法を用 いて検証した場合, 黒人の顔写真呈示に対してポジテ ィブな感情が生起しているのか, それともネガティブ な感情が生起しているのかというように, 誘因価など の上位レベルでの検証分析が可能である。しかし，同 じ誘因価でありながら質的に異なる表象を区別して検 出するようなことは，現段階の技術では困難であろう と思われる。たとえば，呈示された人物に対して好印 象を抱いたことは検出できたとしても，それが“温か い”という印象であったのか，それとも“有能だ”と いう印象であったのかは区別しがたい。このような制 約を受けてか，社会神経科学の研究論文の多くが誘因 価などの上位概念レベルの分析に留まっており，特性 概念などのより具体的な下位概念の表象はあまり扱わ れていない。しかし，社会的認知を解明していく上で, 具体的な心的表象の役割を看過するわけにはいかない であろう。人間の社会生活に関わる心理がこれほどに 豊かで繊細なものでありうるのは，人間が莫大な量か つ多彩な心的表象を保持し，それらを巧妙に使い分け ているからである。たとえば，他者を“温かい”とと らえているのか, それとも“有能だ”ととらえている のかの違いに応じて，その相手に対する対応のしかた は大きく変化するはずである (Fiske, Cubby, Glick, \& $\mathrm{Xu}, 2002)$ 。このような質的差異を詳細に検証するこ とにこそ, 人間の社会的認知を研究する面白さがある と筆者は考える。むしろ, 特性概念などの具体的なレ
ベルの心的表象を頻繁に扱つてきたのは，従来の社会 心理学である。社会心理学者は, 単語完成課題やス卜 ループ課題などの技法を用いて, 活性化された心的表 象の質的差異について, ある程度の精密さを持って検 出してきた。このような社会心理学的手法を併用しつ つ, 今後の社会神経科学が質的に多彩な心的表象の活 性化という問題について, さらに深く踏み込んだアプ ローチを取るようになることを期待したい。

本文中で論じてきたとおり, 社会神経科学の誕生に よって,これまで社会心理学の手法によって専ら研究 されてきた社会的認知という分野に，仮説的構成概念 の検証・プロセスモデルの検証・非意識的プロセスの 検証という 3 点において大きな恩恵がもたらされた。 そして今後も, この 3 点のみに限らない様々な方向性 から, 社会的認知研究に多大な影響力をもたらしてい くものと思われる。このような影響力を理解すること を通じて，この分野の将来的な可能性や方向性を見極 めていくことが, 今後のさらなる研究発展のために重 要なポイントとなるであろう。そのような思いをめぐ らすために，本稿がひとつのきっかけとなれば幸いで ある。

\section{References}

Blascovich, J. (2008). Challenge and threat. In A. J. Elliot (Ed.), Handbook of Approach and Avoidance Motivation (pp. 431-445). New York; Psychology Press.

Blascovich, J., Mendes, W. B., Hunter, S. B., \& Salomon, K. (1999). Social "facilitation" as challenge and threat. Journal of Personality and Social Psychology, 77, 68-77.

Blascovich, J., \& Tomaka, J. (1996). The biopsychosocial model of arousal regulation. In M. Zanna (Ed.). Advances in Experimental Social Psychology (Vol. 28, pp. 1-51). New York: Academic Press.

Bond, C. F., \& Titus, L. J. (1983). Social facilitation: A meta-analysis of 241 studies. Psychological Bulletin, 94, 265-292.

Brewer, M. B. (1988). A dual process model of impression formation. In T. K. Srull \& R. S. Wyer, Jr. (Eds.), A Dual Process Model of Impression Formation: Advances in Social Cognition (Vol. 1, pp. 1-36). Hillsdale: Lawrence Erlbaum.

Brewer, M. B., \& Harasty Feinstein, A. S. (1999). Dual 
processes in cognitive representation of persons and social categories. In S. Chaiken \& Y. Trope. (Eds.), Dual process theories in social psychology (pp. 255-270). New York; Guilford.

Cacioppo, J. T., \& Berntson, G. G. (1992). Social psychological contributions to the decade of the brain: Doctrine of multilevel analysis. American Psychologist, 47, 1019-1028.

Dunning, D. (1993). Words to live by: the self and definitions of social concepts and categories. In J. M. Suls (Ed.), Psychological perspectives on the self (Vol. 4, pp. 99-126). Hillsdale: Laurence Erlbaum.

Fiske, S. T. (1988). Compare and contrast: Brewer's dualprocess model and Fiske et al.'scontinuum model. In T. K. Srull, \& R. S. Wyer (Eds.), A Dual Process Model of Impression Formation: Advances in Social Cognition (Vol. 1, pp. 65-76). Hillsdale: Lawrence Erlbaum.

Fiske, S. T., Cubby, A. J., Glick, P., \& Xu, J. (2002). A model of (often mixed) stereotype content: Competence and warmth respectively follow from perceived status and competition. Journal of Personality and Social Psychology, 82, 878-902.

Fiske, S. T., Gilbert, D. T., \& Lindzey, G. (Eds.) (2010). Handbook of Social Psychology (5th ed.). New York: Wiley.

Fiske, S. T., \& Neuberg, S. L. (1990). A continuum of impression formation, from category-based to individuating processes: Influences of information and motivation on attention and interpretation. In M. P. Zanna (Ed.), Advances in experimental social psychology (Vol. 23, pp. 1-74). New York: Academic Press.

Gilbert, D. T. (1989). Thinking lightly about others: Automatic components of the social inference process. In J. S. Uleman \& J. A. Bargh (Eds.), Unintended Thought (pp. 189-211). New York: Guilford Press.

Gilbert, D. T., Fiske, S. T., \& Lindzey, G. (Eds.) (1998). Handbook of Social Psychology (4th ed.). New York: Oxford University Press.

Kahneman, D. (2003). A perspective on judgment and choice: mapping bounded rationality. American Psychologist, 58, 697-720.

Krendl, A. C., Macrae, C. N., Kelley, W. M., Fugelsang, J.
F., \& Heatherton, T. F. (2006). The good, the bad, and the ugly: An fMRI investigation of the functional anatomic correlates of stigma. Social Neuroscience, 1, 5-15.

Kruger, J. (1999). Lake Wobegon be gone! The "belowaverage effect" and the egocentric nature of comparative ability judgments. Journal of Personality and Social Psychology, 77, 221-232.

Kruglanski, A. W., \& Orehek, E. (2007). Annual Review of Psychology, 58, 291-316.

Kruglanski, A. W., \& Thompson, E. P. (1999). Persuasion by a single route: A view from the unimodel. Psychological Inquiry, 10, 83-109.

Libet, B., Wright, E. W., \& Gleason, C. A. (1982). Readiness-potentials preceding unrestricted 'spontaneous' vs. pre-planned voluntary acts. Electroencephalography and Clinical Neurophysiology, 54, 322-335.

Lieberman, M. D., Hariri, A., Jarcho, J. M., Eisenberger, N. I., \& Bookheimer, S. Y. (2005). An fMRI investigation of race-related amygdala activity in African-American and Caucasian-American individuals. Nature Neuroscience, 8, 720-722.

Lieberman, M. D., Gaunt, R., Gilbert, D. T., \& Trope, Y. (2002). Reflection and reflexion: A social cognitive neuroscience approach to attributional inference. Advances in Experimental Social Psychology, 34, 199. 249.

Thibaut, J. W., \& Kelley, H. H. (1959). The Social Psychology of Groups. New York: Wiley.

Trope, Y. (1986). Identification and inferential processes in dispositional attribution. Psychological Review, 93, 239257.

Van Veen, V., Krug, M. K., Schooler, J. W., \& Carter, C. S. (2009). Neural activity predicts attitude change in cognitive dissonance. Nature Neuroscience, 12, 14691474.

Wheeler, M. E., \& Fiske, S. T. (2005) Controlling racial prejudice and stereotyping: Social cognitive goals affect amygdala and stereotype activation. Psychological Science, 16, 56-63.

Zajonc, R. B. (1965). Social facilitation. Science, 149, 269274. 